\title{
Original article \\ Effects of aerobic and resistance exercise intensities on 24-hours blood pressure in normotensive women
}

\author{
Aparecido Pimentel Ferreira \\ Bruno Rafael Martins Campos \\ Paulista University at Brasília, Brazil \\ Édis Rodrigues Junior \\ UNICESP Integrated Colleges, Brazil \\ Guilherme Morais Puga \\ Federal University of Uberlândia, Brazil \\ Ciro José Brito \\ Federal University of Sergipe, Brazil
}

\begin{abstract}
The present study aimed to determine the effect of the intensity of aerobic and resistance exercise on the $24 \mathrm{~h}$ BP response in normotensive women. Twenty-four women (aged $33 \pm 9$ years) performed five experimental sessions in randomized order: CON - no exercise; AE50 - 50\% of heart rate reserve (HRR); AE70 - 70\% of HRR; RE40 - 40\% of 1repetition maximum (RM) and RE70 - 70\% of 1RM. Systolic and diastolic BP and HR measurements were measured during $24 \mathrm{~h}$ post-exercise at the participant's workplace. The AE50, AE70 and RE40 sessions led to the greatest and longest-lasting effects on the SBP, which persisted for up to 24h. For the DBP, the experimental sessions led to similar results; post exercise hypotension was observed until $7 \mathrm{~h}$ post-exercise, with the exception of the AE70 session, which produced effects that persisted for 24h. Results shows that both aerobic and resistance exercise performed during the morning can decrease the mean BP above the baseline lasting 24 hours during a normal daily work. The aerobic exercise performed around $50 \%$ of HRR can better regulate both systolic and diastolic BP in this population.
\end{abstract}

Keywords: post exercise hypotension, resistance exercise, aerobic exercise, women

Resumo- -Efeitos das intensidades de exercícios aeróbios e resistidos nas respostas de pressão arterial durante 24 horas em mulheres normotensas." O objetivo do presente estudo foi determinar os efeitos das intensidades de exercícios aeróbio e resistido nas respostas da pressão arterial de $24 \mathrm{~h}$ em mulheres normotensas. Vinte e quatro mulheres $(33 \pm 9$ anos) participarem de cinco sessões experimentais em ordem randomizada: CON sem exercício; AE50 - 50\% da freqüência cardíaca de reserva (FCR); AE70 - 70\% da FCR; RE40 - 40\% de 1 repetição máxima (RM) e RE70 - 70\% da 1RM. As medidas das pressões sistólica (PAS) e diastólica (PAD) e a FC foram realizadas durante 24h após o exercício no local de trabalho. As sessões AE50, AE70 e RE40 demonstraram maiores e mais duradores efeitos na PAS, e permaneceram ate às $24 \mathrm{~h}$. Já na PAD houve respostas similares, com hipotensão até 7 horas após o exercício. Com exceção da sessão AE70, onde perdurou por 24h. Os resultados demonstraram que ambos os exercícios aeróbicos e resistidos realizados pela manha pode reduzir a PA abaixo da linha base e perdurar por $24 \mathrm{~h}$ durante um dia normal de trabalho. O exercício aeróbio realizado a $50 \%$ da FCR pode proporcionar melhores resultados na regulação de ambas PAS e PAD nessa população.

Palavras-chaves: hipotensão pós exercício, exercício resistido, exercício aeróbio, mulheres

Resumen-"Los efectos de las intensidades del ejercicio aeróbico y resistido en las respuestas de la presión arterial de 24 horas en mujeres normo tensas." El objetivo del presente estudio fue determinar los efectos de las intensidades del ejercicio aeróbico y resistido en las respuestas de la presión arterial de 24 horas en mujeres normo tensas. Veinticuatro mujeres (33 \pm 9 anos) participaron de cinco sesiones experimentales en orden aleatoria: CON - sin ejercicio; AE50 - 50\% de la frecuencia cardiaca de reserva (FCR); AE70 - 70\% de la FCR; RE40 - 40\% de 1 repetición máxima (RM) y RE70 - 70\% de 1RM. Las medidas de la presión sistólica (PAS) y diastólica (PAD) y la FC fueron realizadas durante 24h después del ejercicio en el local de trabajo. Las sesiones AE50, AE70 y RE40 demostraron efectos mayores y mas duraderos en la PAS, y permanecieron durante las 
24h. En la PAD hubiera respuestas similares, con hipotensión hasta 7 horas después del ejercicio. Con excepción de la sesión AE70, donde perduró por 24h. Los resultados demostraron que tanto los ejercicios aeróbicos cuanto los resistidos realizados por la mañana pueden reducir la PA abajo de la línea de base y perdurar por 24h durante un día normal de trabajo. El ejercicio aeróbico realizado a 50\% de la FCR puede proporcionar mejores resultados en la regulación tanto de la PAS cuanto de la PAD en esa populación.

Palabras claves: hipotensión pós ejercicio, ejercício resistido, ejercício aeróbio, mujeres

\section{Introduction}

Physical exercise has been reported to be an important and efficient nonpharmacological strategy for controlling blood pressure (BP) and for preventing and treating cardiovascular diseases, such as arterial hypertension (Anunciação \& Polito, 2011; Kawano, Nakagawa, Onodera, Higuchi, \& Miyachi, 2008; Polito, Farinatti, Lira, \& Nobrega, 2007).

The primary beneficial effect of physical exercise on $\mathrm{BP}$ is the acute reduction in the $\mathrm{BP}$ values that occur during rest after physical exercise performance. This phenomenon is known as post exercise hypotension (PEH) (Halliwill, 2001; MacDonald, 2002). The PEH mechanisms for several types of exercise are associated with decreases in sympathetic activity, cardiac output and stroke volume; furthermore, PEH has been shown to cause a decrease in the total peripheral vascular resistance by stimulating the release of vasodilating substances, such as nitric oxide (Anunciação \& Polito, 2011; Forjaz, Matsudaira, Rodrigues, Nunes, \& Negrão, 1998; Forjaz et al., 2003; Halliwill, 2001).

Many studies have evaluated PEH during the 30 to 120 ms immediately after exercise is completed. According to Halliwill (2001), short-term BP reductions have a minimal impact on an individual's cardiovascular health. Therefore, monitoring an individual's BP for prolonged periods after exercise may reveal a greater number of the benefits that result from PEH.

Despite the results of studies that reveal the acute hypotensive benefits of intense exercise, the results and methodologies used in these studies should be considered carefully because different types, durations and intensities of exercise have been shown to lead to different PEH responses (Anunciação \& Polito, 2011; Cardoso Jr et al., 2010). Controversial data on the magnitude and duration of PEH have been reported, and differences in these parameters have been shown to be related to variations in the methodologies that were used in each study (Anunciação \& Polito, 2011; Cardoso Jr et al., 2010; Hamer, 2006). In contrast, the data pertaining to PEH responses during aerobic exercise are more consistent in the literature, however, the interaction between aerobic and resistance exercises at different intensities and for extended periods of time needs to be investigated further. Therefore, the present study aimed to determine the effect of the intensity of aerobic and resistance exercise on the 24-h blood pressure response in normotensive women.

\section{Methods}

The present study was approved by the local Ethics Committee on Human Research (342/09 CEP/ICS/UNIP). The participants gave their informed consent after they were informed about the purposes, procedures and possible risks associated with the study.

\section{Participants}

After the International Physical Activity Questionnaire (IPAQ) was administered and the clinical histories were obtained, the cohort consisted of 24 normotensive sedentary women. None of the participants presented with diseases or problems that would compromise their physical state (as assessed by the doctor), smoked or used medication that would interfere with the hemodynamic variables that were investigated in the present study.

\section{Procedures}

Preliminary tests: Prior to physical exercise testing, the participants were familiarized with the equipment and ergometers that were used in the present study. The familiarization session consisted of resistance exercise (three sets of 10 repetitions with an intensity between 12 and 14 on the Borg (1982) scale) and aerobic exercise on a treadmill for $30 \mathrm{~min}$, with an intensity of $60 \%$ of the heart rate reserve (HRR).

After familiarizing the participants with the study procedures, we performed a test to determine each participant's one-repetition maximum (1RM) during resistance exercise (Nieman, 2002). In addition, each participant performed a submaximal incremental test on a treadmill at an initial speed of $4 \mathrm{~km} / \mathrm{h}$ that was increased by $0.5 \mathrm{~km} / \mathrm{h}$ increments every $3 \mathrm{~min}$. These increases were conducted until the participant reached $85 \%$ of her predicted maximum heart rate, as determined by the following equation: 220 - the participant's age. The participant's heart rate (HR) was recorded every $20 \mathrm{~s}$ and was averaged for each stage of the experiment. The aerobic exercise sessions were conducted according to the participants' heart rate reserve (HRR).

Intense experimental sessions. After the preliminary tests, the participants performed four experimental sessions of exercise in a randomized order, with at least $48 \mathrm{~h}$ elapsing between the sessions. The sessions included the 
following activities:

. (AE50) - Low-intensity aerobic exercise at 50\% of HRR:

. (AE70) - Moderate-intensity aerobic exercise at $70 \%$ of HRR;

. (RE40) - Low-intensity resistance exercise at $40 \%$ of $1 \mathrm{RM}$;

(RE70) - Moderate-intensity resistance exercise at $70 \%$ of $1 \mathrm{RM}$.

In addition to the aerobic and resistance exercise sessions, the participants also performed a fifth control session $(\mathrm{CON})$ that involved no exercise and required the participants to remain seated during the intervention period. The control session was randomized in a similar manner to the experimental sessions. All of the participants were instructed to refrain from strenuous exercise $24 \mathrm{~h}$ before the experiment and to maintain their normal diet throughout the study period.

During the experimental sessions, the participants arrived at the laboratory $90 \mathrm{~min}$ prior to the start of the workday. After $15 \mathrm{~min}$ in a sitting position, each participant's systolic blood pressure (SBP), diastolic blood pressure (DBP) and resting HR were measured, and the physical exercise was initiated (with the exception of the control day). SBP, DBP and HR measurements were also performed immediately after exercise. These measurements were also conducted every 15 min during the 60min period after the intervention in a sitting position in the laboratory. After the measurements were taken in the study laboratory, three additional SBP, DBP and HR measurements were taken 3,7 and $24 \mathrm{~h}$ post-exercise at the participant's workplace.

During the experimental sessions, the participants were asked to avoid caffeine, alcohol and high salt consumption while maintaining their regular diet. The participants' food and fluid intakes were not restricted (ad libitum), but the participants were asked to record their intake in a food diary. Using this record, the participants were asked to eat the same amounts of food at the same times of day on the remaining experiment days.

Resistance exercise. The resistance exercise in the present study was circuit exercises on High On equipment (Righetto, BRA) and involved five types of exercises: leg extensions, vertical bench presses, leg curls, lat pull-downs and 45-degree leg presses. The circuit was comprised of four sets of each exercise, with 20 repetitions for the RE40 session and 12 repetitions for the RE70 session. Each repetition required $3 \mathrm{~s}$ for the complete movement (concentric and eccentric phase). Forty-five-second rest intervals between exercises and 90 -s rest intervals between circuits were used during the resistance exercise sessions.

Aerobic exercise. The aerobic exercise sessions were performed on an RT 250 treadmill (Movement, BRA) and lasted $30 \mathrm{~min}$ for the AE70 session. The distance covered during the AE70 session was used to determine the length of the AE50 session. For the AE70 session, the exercise was performed at a speed of $7.0 \pm 0.7 \mathrm{~km} / \mathrm{h}$ for a distance of $3.5 \pm 0.3 \mathrm{~km}$. The AE50 session lasted $36.7 \pm 1.3 \mathrm{~min}$ at a speed of $5.7 \pm 0.4 \mathrm{~km} / \mathrm{h}$ for a distance of $3.5 \pm 0.3 \mathrm{~km}$. The speeds for the AE50 and AE70 sessions were determined during the submaximal incremental test and corresponded to $50 \%$ and $70 \%$ of the HRR, respectively.

For the control session, the participants remained seated for $40 \mathrm{~min}$; during this time period, they were allowed to read and talk normally.

\section{Data analysis}

The SBP and DBP were measured using the auscultatory method with a Premium model sphygmomanometer (Glicomed, BRA). These measurements were taken with the participant in a seated position and the participant's right arm supported at heart level, following the Brazilian Society of Cardiology guidelines. The participant's HR was monitored using an S810 heart rate monitor (Polar, FIN). All of the measurements were taken after the participant rested for 15 min while seated.

\section{Statistical analysis}

The data are reported as the means and standard deviations $( \pm \mathrm{SD})$. After the normality test, the BP behavior was determined for the two exercise modalities (aerobic and resistance) and the control day using an analysis of variance with repeated measures and a post-hoc Tukey's test.

The area under the curve (AUC) was calculated using the trapezoidal formula. After the normality test, the variables were analyzed using an analysis of variance with repeated measures and a post-hoc least significance difference (LSD) test.

A $p$-value $<0.05$ was considered to be statistically significant. The data were analyzed using the statistical software SPSS 11.5.

\section{Results}

The participants' anthropometric characteristics, ages and resting blood pressure values are shown in Table 1.

The variations in the differences between the SBP, DBP and MBP at rest, immediately after exercise and during the $24 \mathrm{~h}$ post-exercise recovery period are shown in Figure 1. In this analysis, the change was calculated based on the control day, therefore, the variances are plotted in Figure 1 as the difference between the experimental exercise sessions and the control day at each time point.

After analyzing the variations in the SBP changes, we found that the RE40, AE50 and AE70 sessions resulted in lower values of change compared with the control session for the $45 \mathrm{~min}$ to $24 \mathrm{~h}$ postexercise period, and the RE70 session resulted in lower values of change compared with 
Table 1. Characteristics of the participants. BW - body weight; BMI body mass index; SBP - systolic blood pressure; DBP - diastolic blood pressure; MAP - mean arterial pressure.

\begin{tabular}{cccccccc}
\hline & BW & Height & BMI & Age & SBP & DBP & MBP \\
\hline & $\mathrm{kg}$ & $\mathrm{m}$ & $\mathrm{kg} / \mathrm{m}^{2}$ & years & $\mathrm{mmHg}$ & $\mathrm{mmHg}$ & $\mathrm{mmHg}$ \\
\hline Mean & 65.3 & 1.64 & 24.3 & 33 & 116 & 79 & 92 \\
$\pm \mathrm{SD}$ & 7.0 & 5.6 & 1.7 & 9 & 4 & 9 & 6 \\
\hline
\end{tabular}

the control session at 3 and $7 \mathrm{~h}$ postexercise. The DBP change variations after the AE50 and AE70 sessions were significantly smaller than the control session values after 30 min. The RE40 and RE70 sessions led to lower values after 45 min compared to the control session, although the effects of both the RE40 and RE70 sessions lasted approximately $7 \mathrm{~h}$. In addition, the RE70 session the resulted in an attenuation of SBP that persisted for $24 \mathrm{~h}$. The average BP value for all of the exercise sessions revealed attenuation in this value for up to $24 \mathrm{~h}$ postexercise. For the AE50 session, this effect began at $15 \mathrm{~min}$;

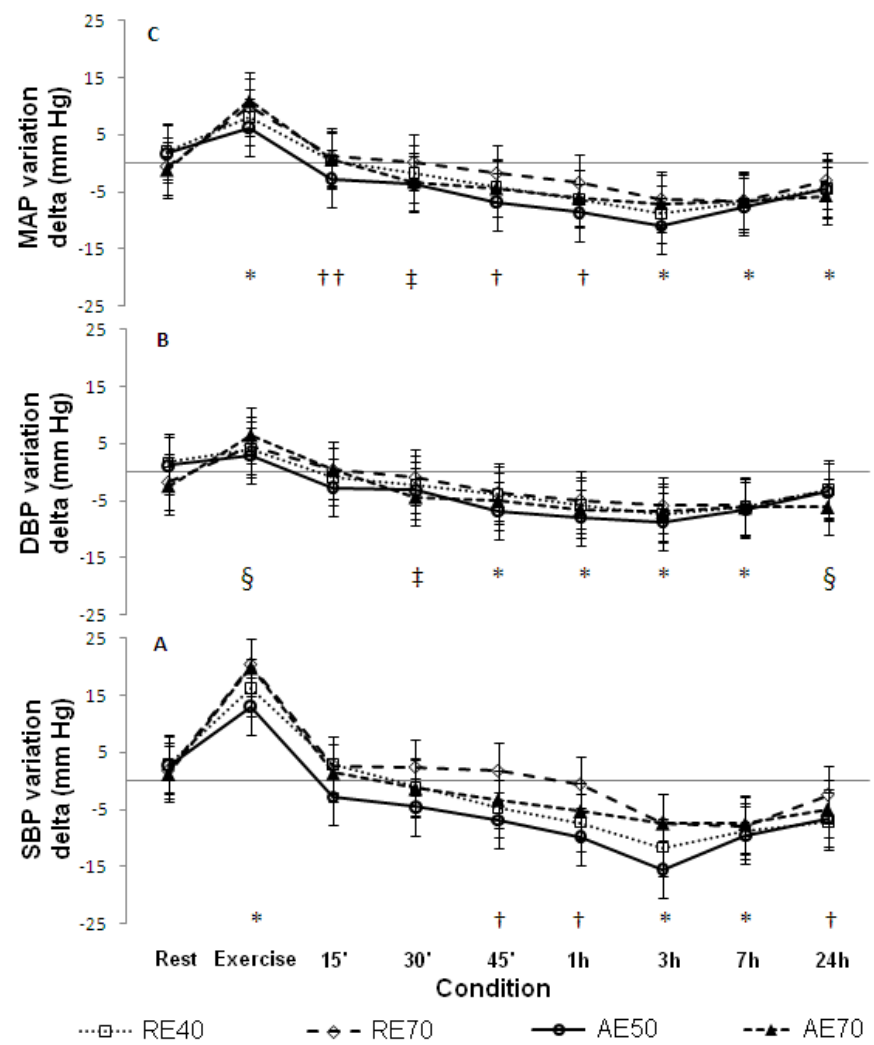

Figure 1. Variation in the changes in (A) the systolic blood pressure, (B) diastolic blood pressure and (C) mean blood pressure for the four experimental sessions compared to the control session over a 24 -h period. $* p<0.05$; significant difference between the control session and the four exercise sessions. $\dagger p<0.05$; significant difference between the control session and the RE40, AE50 and AE70 sessions. $\ddagger p<0.05$; significant difference between the control session and the AE50 and AE70 sessions. $\S p<0.05$; significant difference between the control session and the AE70 session. tt $p<0.05$; significant difference between the control session and the AE50 session. for the AE70 session, this effect began at $30 \mathrm{~min}$; for the RE40 session, this effect began at $45 \mathrm{~min}$; and for the RE70 session, this effect began at $3 \mathrm{~h}$ post-exercise.

The results for the AUC for the SBP, DAP and MAP values pre-exercise, immediately after exercise and $24 \mathrm{~h}$ after exercise during the experimental and control sessions are shown in Figure 2.

The AUC for the SBP during the AE50 session was significantly lower than that observed during the RE70 session and the control session. The AUC for the DBP during the AE50 session was significantly lower than that for the control session, and the AUCs for the MAP during the AE50, AE70 and RE70 sessions were lower than that for the control session.

\section{Discussion}

The present study examined the effects of low-intensity resistance exercise (performed at $40 \%$ of $1 \mathrm{RM}$ ), moderateintensity resistance exercise (performed at $70 \%$ of $1 \mathrm{RM}$ ),

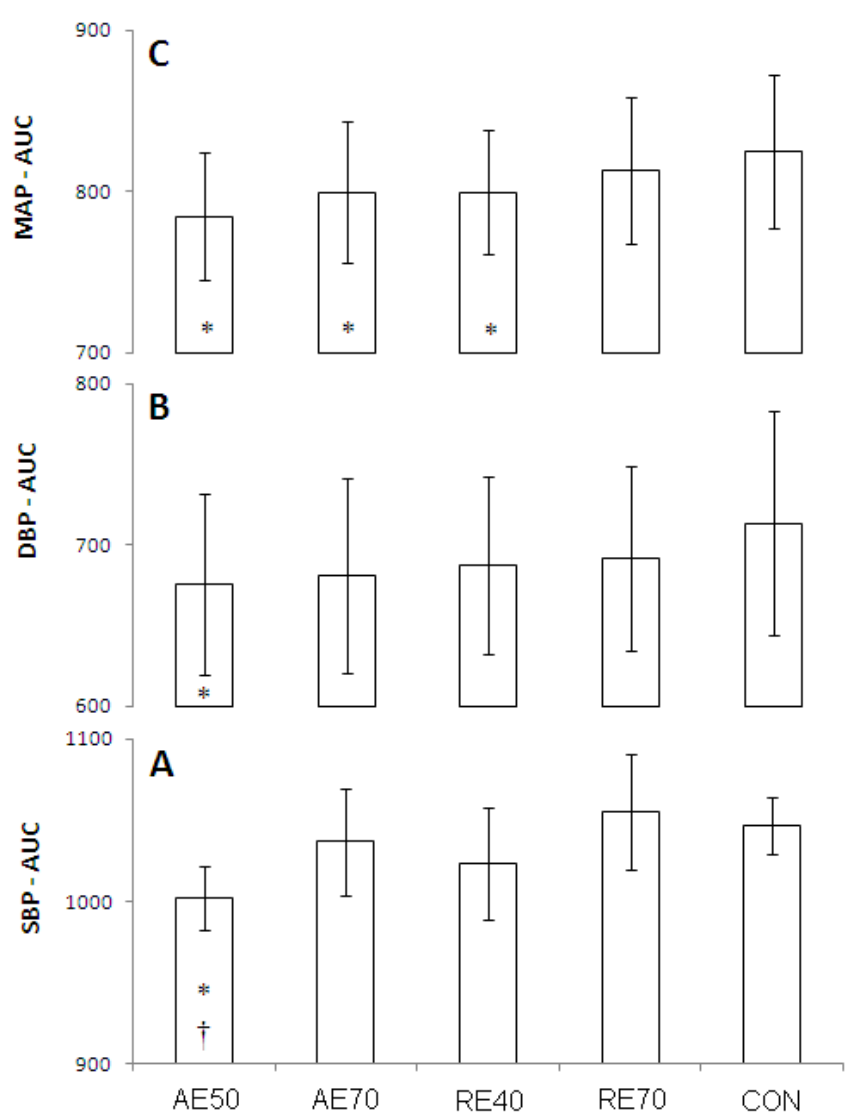

Figure 2. Area under the curve for the systolic blood pressure (A), diastolic blood pressure (B) and mean arterial pressure (C) during the four experimental sessions and the control session over a 24-h period. $* p<0.05$; significantly different compared with the control session. $\uparrow p<0.05$; significantly different compared with the RE70 session. 
low-intensity aerobic exercise (performed at 50\% of the HRR) and moderate-intensity aerobic exercise (performed at $70 \%$ of the HRR) on the SBP and DBP over a 24 -h period in young women during a regular routine of daily activities.

The primary results of the present study show that the AE50, AE70 and RE40 sessions led to the greatest and longest-lasting effects on the SBP, which persisted for up to $24 \mathrm{~h}$. For the DBP, the experimental sessions led to similar results; PEH was observed until $7 \mathrm{~h}$ postexercise, with the exception of the AE70 session, which produced effects that persisted for $24 \mathrm{~h}$. For the MAP, all of the sessions induced PEH for $24 \mathrm{~h}$ post-exercise compared with the control day. These effects only varied in their start time: the PEH that resulted from the AE50 and AE70 sessions began earlier and lasted longer than that after the other sessions. Additionally, the AUC analysis revealed that the AE50 session led to lower PEH values than the control day for the SBP and DBP. The PEH values for the MAP were lower than those on the control day for all of the experimental sessions, except for the RE70 session.

The BP reductions that we observed after a single exercise session are consistent with findings from other studies that have reported PEH after aerobic and resistance exercise in both normotensive and hypertensive individuals (Anunciação \& Polito, 2011; Cardoso Jr et al., 2010). In addition, our study shows that aerobic and resistance exercise can reduce an individual's BP for up to $24 \mathrm{~h}$ during daily activities, which is clinically relevant as a protective mechanism against cardiovascular disease (MacDonald et al., 1999; MacDonald, Hogben, Tarnopolsky, \& MacDougall, 2001; Mota et al., 2009).

The AUC for the SBP over a 24-h period after the AE50 session was significantly lower compared to that for the other experimental sessions. Although there is no consensus in the literature (Anunciação \& Polito, 2011; Cardoso Jr et al., 2010), several studies have reported contradictory results in terms of the $\mathrm{BP}$ responses to exercise intensity. According to these authors, $\mathrm{PEH}$ is the most significant after exercise with a greater aerobic (Cunha et al., 2006; Eicher, Maresh, Tsongalis, Thompson, \& Pescatello, 2010) or resistance intensity (Rezk, Marrache, Tinucci, Mion Jr, \& Forjaz, 2006).

According to Curtis and O'Keefe Jr (2002), higherintensity exercise produces a greater level of $\mathrm{PEH}$, especially during the first few hours after the completion of the exercise. During this period, greater sympathetic autonomic nervous system activation may occur, which results in greater BP values. However, our data show that this phenomenon was not observed, even when the BP was measured at much later time points post-exercise than this previous study.

In contrast, (Jones, George, Edwards, \& Atkinson, 2009) observed no differences in the PEH responses to aerobic exercise at several intensities and durations in young men. Similar results were reported by (Casonatto \& Polito, 2009), demonstrating that, for young men, a session of aerobic exercise at several intensities and durations does not promote differences in the post-exercise BP responses.

In agreement with the results of the present study, Bermudes, Vassallo, Vasquez, and Lima (2004) studied normotensive individuals during sleep and after exercise using ambulatory blood pressure monitoring (ABPM) and found that a single session of either resistance or aerobic exercise promoted $\mathrm{PEH}$ during sleep and after exercise. However, these authors reported that aerobic exercise was more effective than resistance exercise because it promoted more significant reductions in the 24-h BP during waking and sleeping periods.

PEH due to aerobic exercise that is attenuated for $24 \mathrm{~h}$ has been demonstrated mainly in adults of both sexes who were middle-aged or elderly, however, PEH has been shown to have a higher incidence in hypertensive individuals (Ciolac, Guimarães, Bortolotto, Doria, \& Bocchi, 2009; Quinn, 2000; Wallace, Bogle, King, Krasnoff, \& Jastremski, 1999). In contrast, several studies did not report a significant BP reduction over the 24-h period after aerobic exercise in normotensive young women (Forjaz et al., 1998; Pescatello et al., 2008).

Our data show that even in young and middle-aged normotensive women, aerobic exercise can induce PEH and provide cardiovascular protection for up to $24 \mathrm{~h}$. Similar data have been reported by other studies (Bermudes et al., 2004; Forjaz et al., 1998; Forjaz et al., 2003).

Few studies have demonstrated lasting PEH as a result of resistance exercise in young or middle-aged women. (Melo, Alencar Filho, Tinucci, Mion Jr, \& Forjaz, 2006) reported that $\mathrm{PEH}$ lasted $10 \mathrm{~h}$ in middle-aged hypertensive women after a resistance exercise session. Conversely, other studies (Queiroz, Gagliardi, Forjaz, \& Rezk, 2009; Roltsch, Mendez, Wilund, \& Hagberg, 2001) did not observe PEH in normotensive young women. Our study is one of the first to show that resistance exercise, even at low intensities, can induce PEH for up to $24 \mathrm{~h}$ in middleaged, normotensive women.

The majority of these $\mathrm{PEH}$ differences in relation to the intensity of aerobic and resistance exercise arise from differences in the studies' exercise protocols, which make it difficult to accurately draw conclusions about the interaction between the exercise type and intensity and the PEH. However, our results support the presence of this protective mechanism in middle-aged, normotensive women because of both aerobic exercise and resistance exercise at different intensities.

Our results demonstrate that the AE50, AE70 and RE40 sessions effectively attenuated the $\mathrm{BP}$ in normotensive women who maintained their daily activities. This effect may reduce the risk of developing cardiovascular diseases, such as hypertension, especially if the exercise sessions occur regularly. Another indication of cardiovascular protection is indicated by the low values of double product (DP) 3 to $24 \mathrm{~h}$ after the end of the exercise sessions compared with the control day values (data not shown).

The results reported by (Terra et al., 2008) are consistent 
with the relationship between DP and BP that is reported in the present study, given the reduction in these variables during the rest period after resistance training in hypertensive elderly participants. These authors report that a DP reduction after exercise under resting conditions has a significant importance and reduces the risk of cardiovascular problems because exercise may result in reduced cardiovascular work. In the present study, this reduction appears to be mediated by a decrease in the SBP because no significant changes were observed in the $\mathrm{CF}$.

Blood pressure reductions are an important tool for preventing cardiovascular disease and adverse complications associated with hypertension (Jones et al., 2009; Lima et al., 2008; Simões, Moreira, Kushnick, Simões, \& Campbell, 2010). The present study confirms the clinical and preventative relevance of aerobic and resistance exercise that is performed in the morning, prior to an individual's professional activities, in attenuating the BP throughout the day and possibly until the following day. For Brown, Dengel, Hogikyan, and Supiano (2002) and Halliwill (2001), a greater activation of the parasympathetic autonomic nervous system and an increased endothelium-dependent vasodilation mediated by nitric oxide may be two principle mechanisms that explain $\mathrm{PEH}$.

Whelton et al. (2002) claimed that small changes in BP have a major impact on an individual's cardiovascular survival. Therefore, 3 - and 5-mmHg reductions in the SBP may decrease the risk of infarction by $8 \%$ and $14 \%$ and the risk of coronary disease by $5 \%$ and $9 \%$, respectively. In addition, these reductions in the SBP may reduce the overall mortality from all causes by $4 \%$ and $7 \%$, respectively. Additionally, a small, $2-\mathrm{mmHg}$ reduction in the DBP may reduce the hypertension prevalence by $17 \%$ in the general population.

One limitation of the present study was the lack of control over the participants' diets and rest repetitions. Ideally, the participants would have repeated the same diet and daily activities every day during and between experiments. In an attempt to control for this variable, we monitored all of the participants by calling them before the preparation phase to ensure that they complied with the diet they reported during the first experiment.

Based in our results, we conclude that aerobic exercise at 50 and $70 \%$ of the HRR and resistance exercise at $40 \%$ of 1RM produced PEH in the SBP that persisted for up to $24 \mathrm{~h}$. For the DBP, the greatest PEH result was observed after aerobic exercise at $70 \%$ of the HRR, and these PEH effects persisted for up to $24 \mathrm{~h}$. For the other sessions, PEH persisted for up to $7 \mathrm{~h}$ post-exercise. For aerobic and resistance exercise, the MBP reflected $\mathrm{PEH}$ for up to 24 hours.

\section{Practical applications}

Our results shows that both aerobic and resistance exercise performed during the morning, either in low or moderate intensities, can decrease the mean BP above the baseline lasting 24 hours during a normal daily work. Moreover it appears that the aerobic exercise performed around $50 \%$ of HRR (low intensity) can better regulate both systolic and diastolic BP in sedentary women without hypertension diagnostic.

These regulations in the $\mathrm{BP}$ by the exercise are very important even in non-hypertensive individuals, because small changes in BP have a major impact on an individual's cardiovascular survival and protection against the cardiovascular disease development.

\section{References}

Anunciação, P.G., \& Polito, M.D. (2011). Hipotensão pós-exercício em indivíduos hipertensos: uma revisão. Arquivos Brasileiros de Cardiologia, 96(5), e100-e109.

Bermudes, A., Miranda, M.L., Vassallo, D.V., Vasquez, E.C., \& Lima, E.G. (2004). Ambulatory blood pressure monitoring in normotensive individuals undergoing two single exercise sessions: resistive exercise training and aerobic exercise training. Arquivos Brasileiros de Cardiologia, 82(1), 57-64.

Borg, GA. (1982). Psychophysical bases of perceived exertion. Medicine Science in Sports and Exercise, 14(5), 377-381.

Brown, M.D., Dengel, D.R., Hogikyan, R.V., \& Supiano, M.A. (2002). Sympathetic activity and the heterogenous blood pressure response to exercise training in hypertensives. Journal of Applied Physiology, 92(4), 1434-1442.

Cardoso Jr, C.G., Gomides, R.S., Queiroz, A.C., Pinto, L.G., Silveira, F.L., Tinucci, T., . . . de Forjaz, C.L.M. (2010). Acute and chronic effects of aerobic and resistance exercise on ambulatory blood pressure. Clinics, 65(3), 317-325.

Casonatto, J. \& Polito, M.D. (2009). Hipotensão pós-exercício aeróbio: uma revisão sistemática. Revista Brasileira de Medicina do Esporte, 15(2), 151-157.

Ciolac, E.G., Guimarães, G.V., Bortolotto, L.A., Doria, E.L., \& Bocchi, E.A. (2009). Acute effects of continuous and interval aerobic exercise on 24-h ambulatory blood pressure in long-term treated hypertensive patients. International Journal of Cardiology, 133(3), 381-387.

Cunha, G.A., Rios, A.C.S., Moreno, J.R., Braga, P.L., Campbell, C.S.G., Simões, H.G., \& Denadai, M.L.D.R. (2006). Postexercise hypotension in hypertensive individuals submitted to aerobic exercises of alternated intensities and constant intensityexercise. Revista Brasileira de Medicina do Esporte, 12(6), 313-317.

Curtis, B.M., \& O'Keefe Jr, J.H. (2002). Autonomic tone as a cardiovascular risk factor: the dangers of chronic fight or flight. Paper presented at the Mayo Clinic Proceedings.

Eicher, J.D., Maresh, C.M., Tsongalis, G.J., Thompson, P.D., \& Pescatello, L.S. (2010). The additive blood pressure lowering effects of exercise intensity on post-exercise hypotension. American Heart Journal, 160(3), 513-520.

Forjaz, C.L.M., Matsudaira, Y., Rodrigues, F.B., Nunes, N., \& Negrão, C.E. (1998). Post-exercise changes in blood pressure, heart rate and rate pressure product at different exercise intensities in normotensive humans. Brazilian Journal of Medical and Biological Research, 31(10), 1247-1255.

Forjaz, C.L.M., Rezk, C.C., Melo, C.M., Santos, D.A., Teixeira, L., Nery, S.S., \& Tinucci, T. (2003). Exercício resistido para o paciente hipertenso: indicação ou contra-indicação. Revista Brasileira de Hipertensão, 10(2), 119-124. 
Halliwill, J.R. (2001). Mechanisms and clinical implications of postexercise hypotension in humans. Exercise and Sport Sciences Reviews, 29(2), 65-70.

Hamer, M. (2006). The anti-hypertensive effects of exercise. Sports Medicine, 36(2), 109-116.

Jones, H., George, K., Edwards, B., \& Atkinson, G. (2009). Exercise intensity and blood pressure during sleep. International Journal of Sports Medicine, 30(2), 94-99.

Kawano, H., Nakagawa, H., Onodera, S., Higuchi, M., \& Miyachi, M. (2008). Attenuated increases in blood pressure by dynamic resistance exercise in middle-aged men. Hypertension Research, 31(5), 1045-1053.

Lima, L.C.J., Assis, G.V., Hiyane, W., Almeida, W.S., Arsa, G., Baldissera, V., . . S Simões, H.G. (2008). Hypotensive effects of exercise performed around anaerobic threshold in type 2 diabetic patients. Diabetes Research and Clinical Practice, 81(2), 216222.

MacDonald, J.R., MacDougall, J., Duncan, I., Stephen, A., Smith, K.M., McCartney, N., Moroz, J.S., . . . Tarnopolsky, M.A. (1999). Hypotension following mild bouts of resistance exercise and submaximal dynamic exercise. European Journal of Applied Physiology and Occupational Physiology, 79(2), 148-154.

MacDonald, J.R. (2002). Potential causes, mechanisms, and implications of post exercise hypotension. Journal of Human Hypertension, 16(4), 225-236.

MacDonald, J.R., Hogben, C.D., Tarnopolsky, M.A., \& MacDougall, J.D. (2001). Post exercise hypotension is sustained during subsequent bouts of mild exercise and simulated activities of daily living. Journal of Human Hypertension, 15(8), 567-571.

Melo, C.M., Alencar Filho, A.C., Tinucci, T., Mion Jr, D., \& Forjaz, C.LM. (2006). Postexercise hypotension induced by low-intensity resistance exercise in hypertensive women receiving captopril. Blood Pressure Monitoring, 11(4), 183-189.

Mota, M.R., Pardono, E., L., Laila C.J., Arsa, G., Bottaro, M., Campbell, C.S.G., \& Simões, H.G. (2009). Effects of treadmill running and resistance exercises on lowering blood pressure during the daily work of hypertensive subjects. The Journal of Strength \& Conditioning Research, 23(8), 2331-2338.

Nieman, D. (2002). Exercise Testing and Prescription: A HealthRelated Approach (Vol. 4). New York: McGraw-Hill.

Pescatello, L.S., Blanchard, B.E., Van Heest, J.L., Maresh, C.M, Gordish-Dressman, H., \& Thompson, P.D. (2008). The metabolic syndrome and the immediate antihypertensive effects of aerobic exercise: a randomized control design. BMC Cardiovascular Disorders, 8(1), 12.

Polito, M.D., Farinatti, P.T.V., Lira, V.A., \& Nobrega, A.C.L. (2007). Blood pressure assessment during resistance exercise: comparison between auscultation and Finapres. Blood Pressure Monitoring, 12(2), 81-86.

Queiroz, A.C.C., Gagliardi, J.F.L., Forjaz, C.L.M., \& Rezk, C.C. (2009). Clinic and ambulatory blood pressure responses after resistance exercise. The Journal of Strength \& Conditioning Research, 23(2), 571-578.

Quinn, T.J. (2000). Twenty-four hour, ambulatory blood pressure responses following acute exercise: impact of exercise intensity. Journal of Human Hypertension, 14(9), 547-553.

Rezk, C.C., Marrache, R.C.B., Tinucci, T., Mion Jr, D., \& Forjaz, C.L.M. (2006). Post-resistance exercise hypotension, hemodynamics, and heart rate variability: influence of exercise intensity. European Journal of Applied Physiology, 98(1), 105-112.

Roltsch, M.H., Mendez, T., Wilund, K.R., \& Hagberg, J.M. (2001). Acute resistive exercise does not affect ambulatory blood pressure in young men and women. Medicine and Science in Sports and Exercise, 33(6), 881-886.

Simões, G.C., Moreira, S.R., Kushnick, M.R., Simões, H.G, \& Campbell, C.S.G. (2010). Postresistance exercise blood pressure reduction is influenced by exercise intensity in type-2 diabetic and nondiabetic individuals. The Journal of Strength \& Conditioning Research, 24(5), 1277-1284.

Terra, D.F., Mota, M.R., Rabelo, H.T., Bezerra, L.M A., Lima, R.M., Ribeiro, A.G., . . Silva, F.M. (2008). Reduction of arterial pressure and double product at rest after resistance exercise training in elderly hypertensive women. Arquivos Brasileiros de Cardiologia, 91(5), 299-305.

Wallace, J.P., Bogle, P.G., King, B.A., Krasnoff, J.B., \& Jastremski, C.A. (1999). The magnitude and duration of ambulatory blood pressure reduction following acute exercise. Journal of Human Hypertension, 13(6), 361-366.

Whelton, P.K., He, J., Appel, L.J., Cutler, J.A., Havas, S., Kotchen, T.A., ... Winston, M.C. (2002). National High Blood Pressure Education Program Coordinating Committee: Primary prevention of hypertension: Clinical and public health advisory from the national high blood pressure education program. JAMA, 288(15), 1882-1888.

\section{Authors' note}

Aparecido Pimentel Ferreira (cidopimentel@yahoo.com.br) is with the Núcleo Interdisciplinar de Pesquisa (NIP), Faculdades Integradas Promove de Brasília e Instituto Superior de Educação do ICESP. Grupo de Estudos em Fisiologia do Exercício e Saúde - GEFES, Universidade Paulista. Brasília, DF.

Bruno Rafael Martins Campos (brunormc@gmail.com) is with the Grupo de Estudos em Fisiologia do Exercício e Saúde - GEFES, Universidade Paulista. Brasília, DF. Paulista University at Brasilia, Brazil.

Édis Rodrigues Junior (edisrodrigues.junior@yahoo.com.br) is with the Núcleo Interdisciplinar de Pesquisa - NIP, Faculdades Integradas Promove de Brasília, Brasília, DF. (UNICESP Integrated Colleges).

Guilherme Morais Puga (gmpuga@gmail.com) is with the Federal University of Uberlândia, Brazil.

Ciro José Brito (cirojbrito@gmail.com) is with the Departamento de Educação Física, Federal University of Sergipe, Brazil.

\section{Correspondence to:}

Aparecido Pimentel Ferreira

Quadra 210, lote 2, Residencial Cris Village, apartamento 1704. Águas Claras - Brasília - DF, CEP 71930-750

(61) $8142-8877$

cidopimentel@yahoo.com.br

Manuscript received on June 4, 2012

Manuscript accepted on July 25, 2013

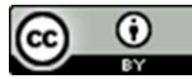

Motriz. Journal of Physical Education. UNESP, Rio Claro, SP, Brazil, eISSN: 1980-6574, is licenced under a Creative Commons License, Version 3.0. 